\title{
Endoscopic assisted facial rejuvenation: a 35 year personal journey
}

\author{
Oscar M. Ramirez \\ Department Plastic Surgery Cleveland Clinic Florida, Adjunct Clinical Faculty, Cleveland Clinic, FL 33331, USA. \\ Correspondence to: Dr. Oscar M. Ramirez, Ramirez Plastic Surgery, 19495 Biscayne Blvd, Ste. 200, Aventura, FL 33180, USA. \\ E-mail: ramirezmdps@gmail.com
}

How to cite this article: Ramirez OM. Endoscopic assisted facial rejuvenation: a 35 year personal journey. Plast Aesthet Res 2020;7:25. http://dx.doi.org/10.20517/2347-9264.2019.78

Received: 26 Dec 2019 First Decision: 23 Mar 2020 Revised: 10 Apr 2020 Accepted: 7 May 2020 Published: 23 May 2020

Science Editor: Kai O. Kaye, John Yousif Copy Editor: Jing-Wen Zhang Production Editor: Jing Yu

\begin{abstract}
Aim: Traditional facelift techniques rely on pulling. They approach the superficial or intermediate layers where the facial nerves and muscles are located, increasing the risk of facial nerve injury. They approach the central oval from the periphery and produce unnatural vectors of pull and aesthetic results. Alternative techniques that work on the subperiosteal plane using endoscopic techniques are described. Modern concepts of volume augmentation, beautification and rejuvenation of the facial expression are an inherent part of such techniques, or can be easily integrated.
\end{abstract}

Methods: The central oval is approached via four small scalp incisions and additional intraoral, upper gingivobuccal incisions. The interconnected frontal subperiosteal, temporal subfascial and midface subperiosteal areas are lifted, imbricated and suspended sequentially. The brow/forehead is suspended to the skull using cortical screws. The midface and lower periorbita are suspended to the fascia of the temporal muscle. The buccal fat pad is used to enhance the ogee line of the midface. Other three-dimensional volumetric maneuvers can easily be applied. In this setting, upper and lower lid blepharoplasties become more straightforward, skin only procedures. Actinic or nicotine damaged skin can be treated with lasers, peels or fluidified fat grafting in the same setting. The excess skin on the lower face and neck can be redrapped with standard cervicofacial techniques. Deep subplatysmal cervicoplasty can be done concomitantly, or at another time to complete comprehensive rejuvenation.

Results: The procedures described herein has been performed in 824 patients with excellent aesthetic results and low complication rate. The average rate of rejuvenation was 18 years. 
Conclusion: These combination techniques are called Biplanar Endoscopic Assisted Mask and Triplanar Endoscopic Assisted Mask facial rejuvenation. They are advanced techniques of facial rejuvenation that provide comprehensive, natural, long lasting results.

Keywords: Endoscopic face lift, videoendoscopy, facial rejuvenation, high definition face, picograft, ogee face, midface

\section{INTRODUCTION}

The procedures, concepts and principles described in this article were developed over a 35 year period, beginning during my Plastic Surgery residency at the University of Pittsburgh. The driving force behind the innovations described in this article were the unnatural, in vogue facelift results of that era.

Traditionally, the aging face was approached using techniques that pulled and stretched the facial soft tissues. The face was approached in a superficial plane, tightening the skin and SMAS (superficial muscular aponeurotic system) only ${ }^{[1-3]}$. Over time, face lift techniques beneath the SMAS evolved, including the deep plane facelift or composite facelift ${ }^{[4,5]}$. Initially, some surgeons considered this technique unsafe, and were hesitant to go deep to SMAS due to the proximity of facial nerve branches ${ }^{[6]}$. Moreover, the degree of facial edema was considered more marked using intermediate layer techniques. Around the same time, Paul Tessier described and popularized the subperiosteal approach ${ }^{[7-12]}$. I first described my five experience into the subperiosteal technique at the 1989 Biannual Congress of the International Society for Aesthetic Plastic Surgery in Zurich, Switzerland, and the 1990 American Society for Aesthetic Plastic Surgery Annual Congress in Chicago Illinois ${ }^{[13]}$. Another paradigm shift that influenced my thinking was the endoscopic approach to the forehead pioneered by Luis Vasconez ${ }^{[14]}$. This was first presented at the 1992 annual meeting of the American Society of Plastic and Reconstructive Surgeons, in Washington DC. I quickly adopted and modified Vasconez's forehead rejuvenation technique ${ }^{[14]}$. Noticing the advantages of the endoforehead compared to the traditional coronal approach I extended the application of the endoscopic approach to total facial rejuvenation ${ }^{[15-18]}$. It became clear that the subperiosteal plane was better suited to endoscopic techniques including secondary rhytidectomies ${ }^{[19]}$. It also made it safer and easier to add supplementary techniques. Those are described below ${ }^{[20-24]}$ [Figure 1]. Along the way Adrien Aiache and I discovered the suborbicularis fat that I coined SOOF (sub-orbicularis oculi fat) ${ }^{[25]}$. It was an excellent structure for filling the tear trough and to lift and imbricate the cheek. More recent research regarding the innervation of the lower eyelid orbicularis has also been relevant to the endo-midface, and the preservation of function of this muscle was another added benefit of this approach ${ }^{[26]}$. The most important side effects of introducing these new techniques were that surgeons were compelled to compare these with the older techniques. In the process we started to focus more critically on the anatomy and aesthetics of the face $e^{[27,28]}$. We began thinking more about the benefits of volume preservation and restoration in contrast to the pulling maneuvers of traditional methods ${ }^{[21-24,28,29]}$. This also created a new landscape for developing new minimally invasive techniques and non-invasive techniques, including the use of fillers and neuromodulators as temporary alternatives to surgical approaches ${ }^{[30,31]}$.

Following the realization that loss of volume was an important component of the aging process many surgeons and dermatologists started over filling faces creating an unnatural aesthetic ${ }^{[32]}$. In my opinion we need to swing the pendulum back and treat all features of facial aging in a more balanced approach. Moreover, a comprehensive approach addressing all thirds of the face gives a more natural result than when surgery is performed in a segmental fashion. An endoscopic approach to the face can address the three thirds of the face in a balanced fashion. If the endoscopic approach is insufficient to address all of the components of the aging face, other main or ancillary procedures can be easily integrated without burning any bridges. 


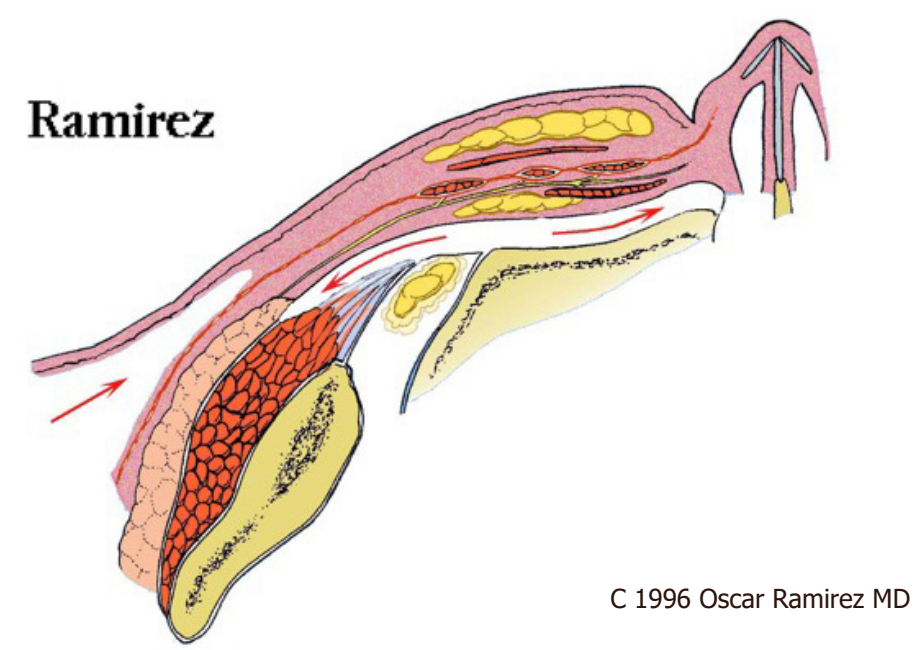

Figure 1. The combination of subperiosteal dissection in the central oval and subcutaneous dissection in the periphery of the face is safest. The intermediate layers where the nerves and the muscles are located are not safe

The endoscopic subperiosteal approach to the aging face can address the forehead/brow, the midface and the lower face around the mandible, i.e., mentopexy. Soft tissue endoscopic cervicoplasty can also be done in younger patients that do not require excisional approaches. In patients over 50 years of age the endoscopic approach becomes the foundation of the rejuvenation and the excess skin of the upper/ lower eyelids, lower face and neck can be removed using standard access incisions. In this setting standard techniques become complementary procedures for a total facial rejuvenation. Likewise, facial implants, fat grafting and laser resurfacing can be easily integrated in the endoscopic subperiosteal facial rejuvenation.

Using these advanced rejuvenation techniques you will achieve the following goals: (1) volume restoration; (2) embellishing; (3) revitalization of facial countenance; (4) lifting of ptotic tissues; (5) tightening of the skin envelope; and (6) volume subtraction, particularly in the neck.

\section{METHODS}

\section{Central oval rejuvenation}

\section{Endoforehead}

Forehead rejuvenation is approached via four scalp incisions, each measuring approximately $1.5-2 \mathrm{~cm}$. Two symmetrical paramedian incisions are also made in the frontal scalp, about $2 \mathrm{~cm}$ from the midline. A final $1.5-2 \mathrm{~cm}$ incision is made in the temporal scalp, at the end of a line from the alar implantation, passing the lateral canthus, and finishing $2-3 \mathrm{~cm}$ inside the temporal hairline. Using triangulation techniques for both the endoscope and the periosteal elevators or endoscopic manipulators, a complete subperiosteal dissection of the frontal bone can be achieved (Ramirez Endoscopic Instruments, Marina Medical. Davie, Florida). This is connected with dissection beneath the tempoparietal fascia. Connection between frontal and temporal areas of dissection is done across the temporal line of fusion, coming from lateral to medial, and not the other way around. The frontal dissection stops when the supraorbital (SON) and supratrochlear (STN) nerves and the associated corrugator muscles are identified. The retaining ligaments of the brow are also elevated off the superolateral orbital rim. Temporal dissection stops at the upper limits of the zygomatic arch. The fat pad that surrounds the temporal nerve are elevated off the deep plane of dissection, ensuring protection of the facial nerve. The sentinel vein and the sensory zygomaticotemporal nerves are preserved. Centrally, $80 \%$ of the corrugator muscles are resected using special muscle biters (Marina Medical. Davie, Florida), ensuring preservation of the SON and STN. The procerus is then transected in a horizontal orientation at the level of the nasoglabellar angle. The periosteum of the frontal bone is cut 


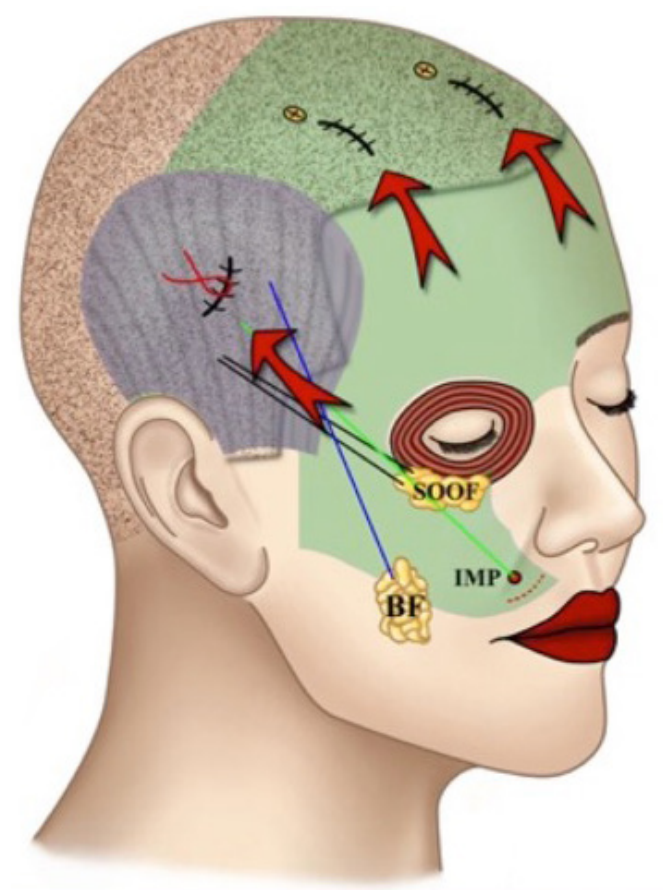

Figure 2. The three-point fixation of the endomidface. Each suture has a specific effect.The combined effect creates a beautiful Ogee line. SOOF: sub-orbicularis oculi fat; BF: Bichat's fat; IMP: inferior Malar Periostium

from one tail of the brow to the other about 5-10 $\mathrm{mm}$ above the arcus marginalis (a variation of the original technique) using "double curved down" Ramirez's endoscopic scissors (Marina Medical. Davie, Florida). A single small butterfly drain is then placed at the level of the glabella. Fixation of the frontotemporal scalp is done after the midface dissection and fixation is complete. The vector of pull is in the superomedial direction.

\section{Endomidface}

The endomidface technique that I proposed many years back accesses the midface using a $2 \mathrm{~cm}$ endoforehead-temporal slit incision and a Caldwell-Luck type incision ${ }^{[22-24,28,29,33]}$. Both incisions are interconnected across the zygoma, therefore avoiding a trans-blepharoplasty approach ${ }^{[34]}$.

The intraoral incision is done vertically at the level of first or second premolar. The subperiosteal dissection of the maxillary and inferior portions of the malar bones was initially done with the Aufricht lighted retractor. The endoscope was introduced to dissect the orbital rim and the rest of the malar bone. Laterally the fascia of the masseter muscle is elevated along the line that continues from the inferior border of the zygoma towards the middle third of the zygomatic arch. This elevates some of the retaining masseteric ligaments and the preparotideal SMAS. Using the temporal and intraoral incisions the pockets created are connected across the zygomatic arch, preserving the infraorbital nerve. The next step is to lift the midface and create volume. Both are accomplished using three structures: (1) Bichat's fat pad; (2) suborbicularis oculi fat (SOOF); and (3) modiolus. Each of these elements is manipulated and suspended using polydioxanone (PDS) 3-0 and 4-0 sutures. Elevation of the Bichat's fat pad elevation over the zygoma augments the convexity of the upper midface, and at the same time creates a concavity of the lower midface. With one maneuver the ogee line of the midface can be recreated [Figures 2 and 3] ${ }^{[29,33]}$. The SOOF overlaps the deep tissues of the midface and effaced any tear trough deformity [Figure 4$]^{[17-25]}$. The modiolus lifts the corner of the mouth [Figure 5] ${ }^{[22-24,33]}$. The Bichat's fat pad suture is piggybacked to the SOOF suture. The SOOF and modiolus sutures, are then anchored to the temporal fascia using the adjustable Peruvian 


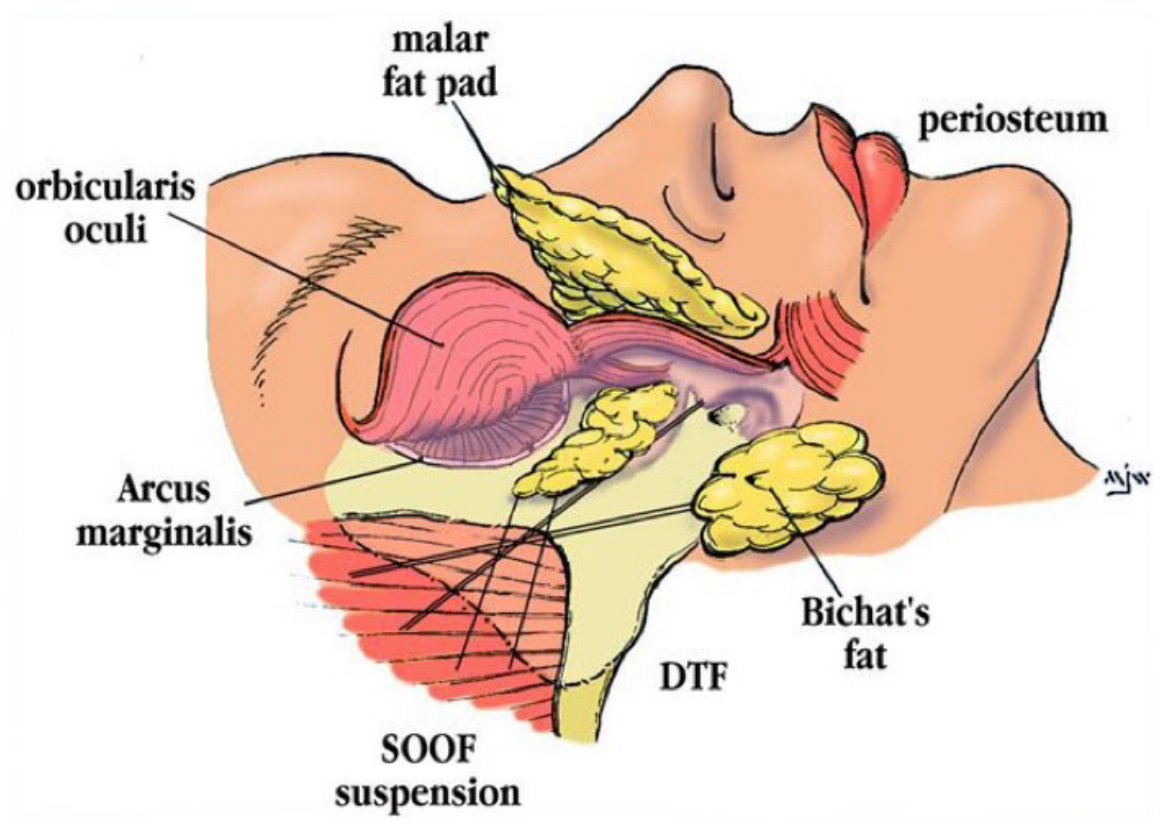

Figure 3. The SOOF suspension lifts the entire cheek and effaces the tear trough deformity. The addition of the Bichat's fat pad accentuates the Ogee line of the face. SOOF: sub-orbicularis oculi fat; DTF: deep temporal fascia

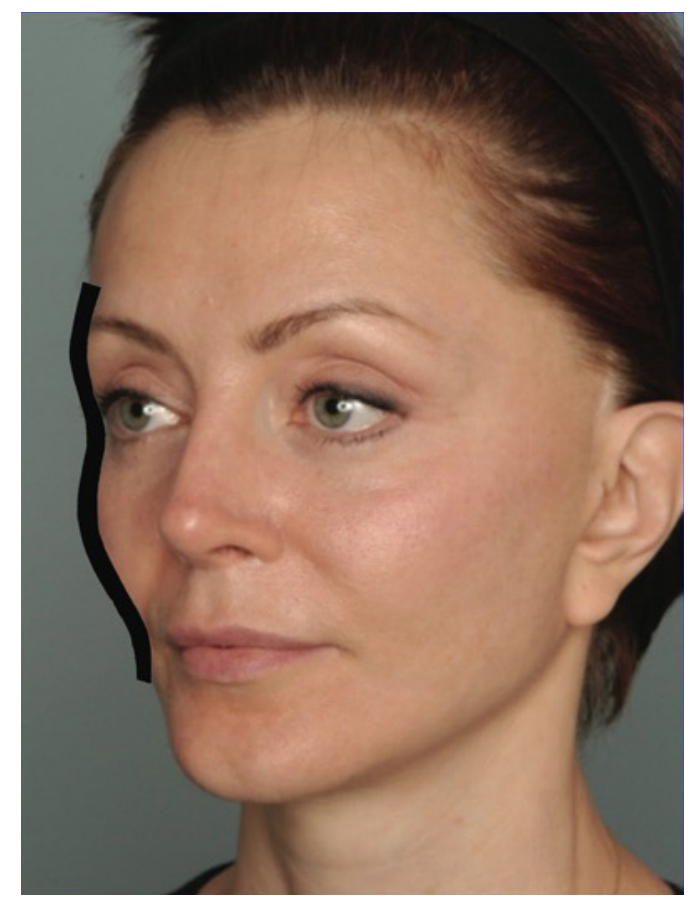

Figure 4. The Ogee line is the curvilinear line of beauty and youth

fisherman's knot $^{[35]}$. This suture controls the proper tension for volume control and desired elevation. A $2 \mathrm{~mm}$ butterfly drain is placed in the midface and fixated to the temporal scalp. The temporoparietal fascia is lifted and anchored to the temporal fascia with 3-0 PDS sutures. This provides additional remodeling of the upper cheek and periorbital region. The intraoral incision is closed with 4-0 chromic catgut sutures. The frontal scalp is suspended with two self-stabilizing Ramirez endoforehead screws (Dupuy Synthes. Warsaw, Indiana). These were applied percutaneously in the frontal scalp away from the access incisions. 


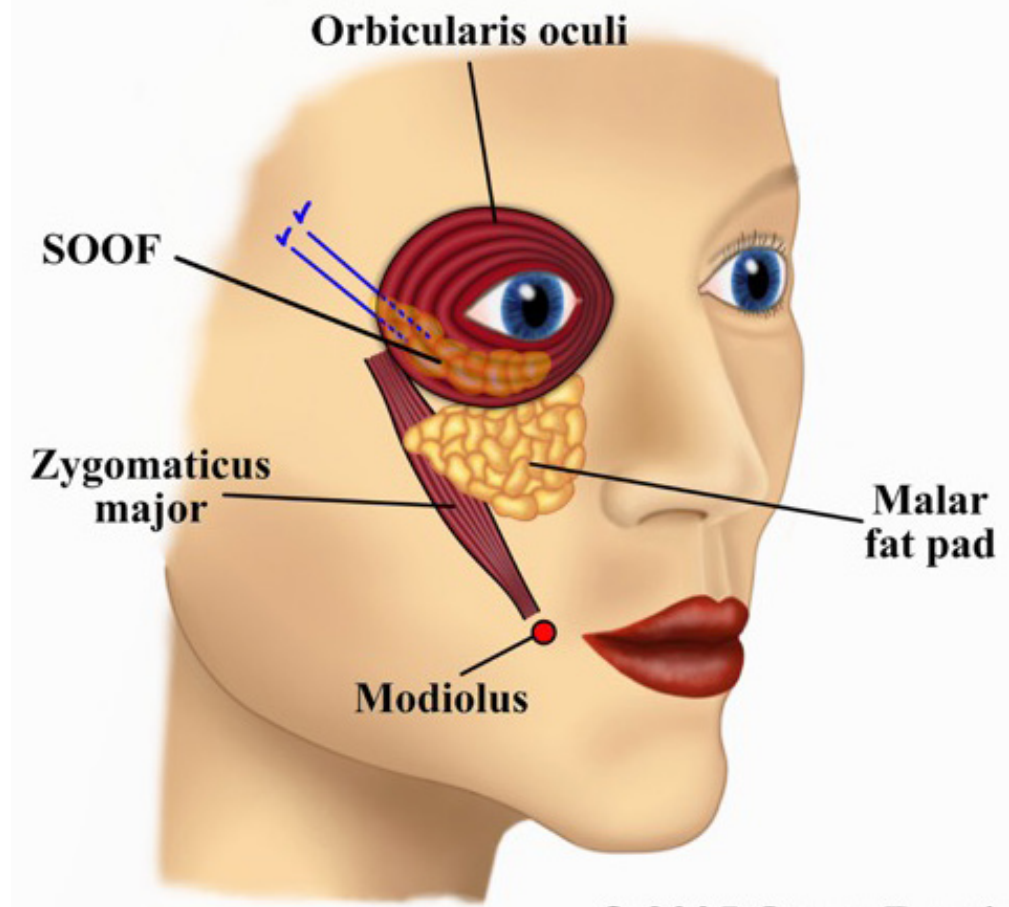

( 2005 Oscar Ramirez M.D.

Figure 5. The subperiosteal repositioning of the orbicularis oculi and the origin of the muscles inserted in the modiolus and the specific suture applied to the area near the modiolus will lift the corner of the mouth. All of these will rejuvenate facial expression. SOOF: suborbicularis oculi fat

\section{Upper blepharoplasty}

Endoforehead lifts the brow and eliminates a small amount of excess skin from the upper eyelid. Greater skin excess will still require an additional blepharoplasty. However, the amount of skin resection was far less than if this was done in isolation. Ptosis of the brow creates apparent or real excess skin in the upper eyelid area area. The apparent excess is reversed with the endoforehead. This will make the need for upper blepharoplasty less likely.

\section{Lower blepharoplasty}

When combined with endomidface, lower blepharoplasty becomes more straight forward procedure. Lateral orbicularis is suspended using a 4-0 nylon suture to the temporal fascia, using a skin only resection. This is done after endomidface fixation. Midface lift has the additional benefit of filling the tear trough, and blending it better with the infraorbital fat. I do not remove any intraorbital fat except under unusual indications, i.e., globular eyes, excessive and protruding lower eyelid fat pads.

\section{Advanced objectives of facial rejuvenation}

The steps of endoscopic central oval rejuvenation (endoforehead-endomidface) and blepharoplasty described above were all performed in patients below 50 years of age. This was the cornerstone over which other techniques were added to provide a more comprehensive rejuvenation in the older cohort of patients. The techniques described above may by themselves attained some of the objectives outlined below. However, other techniques are needed to obtain the following objectives:

\section{Volume enhancement}

Volume augmentation of the face was obtained using one of the following methods: (1) facial implants; (2) imbrication techniques; (3) vascularized fat mobilization; and (4) fat grafting. A representative illustration summarizes these methods [Figure 6]. 


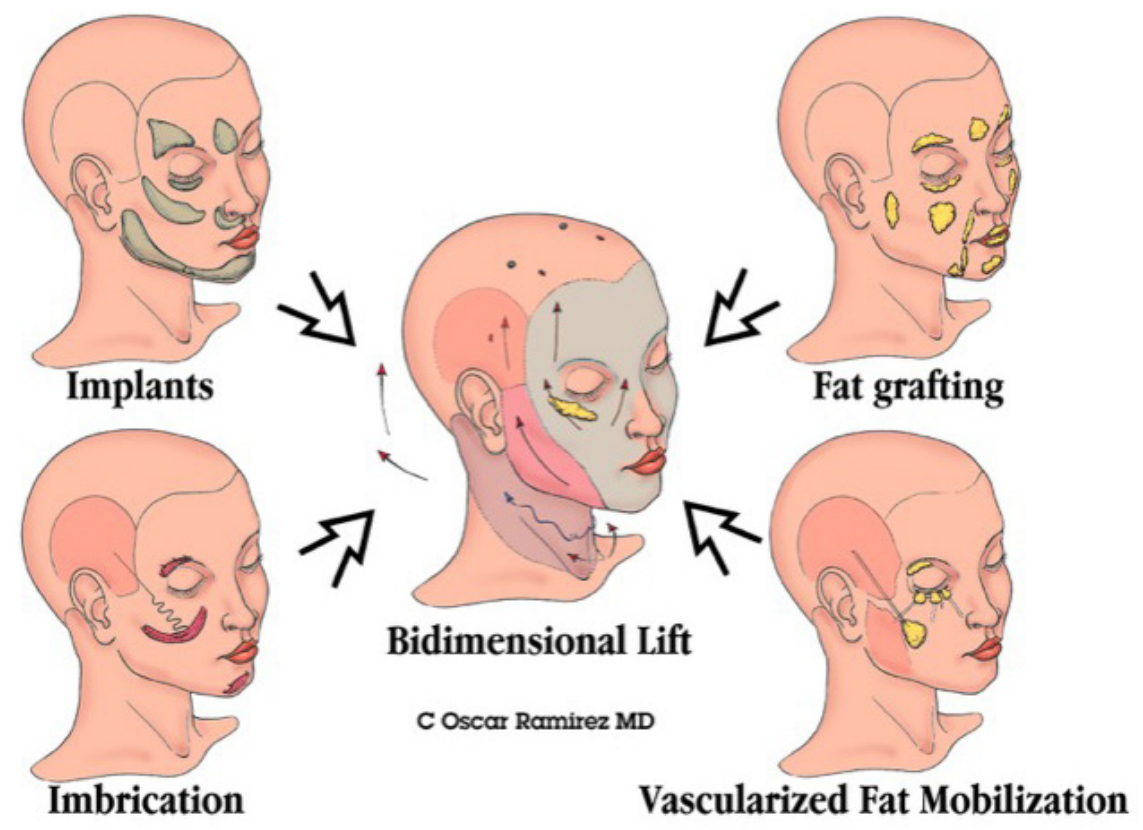

Figure 6. Additional methods of volumetric enhancement that can be applied to the pureendoscopic central oval facial rejuvenation or the biplanar technique (First published in study ${ }^{[22]}$ )

(1) Facial implants. In a previous publication I stated that facial beauty is "bone deep" ${ }^{\text {"[36] }}$. To enhance the facial skeleton my preferred choice of implant material is the porous polypropylene [Medpor (Stryker. Portage, Michigan) Su-Por (Poriferous. Newman, Georgia)]. These implants were found to have a different biological behavior to silicone implants and do not erode bone. The soft tissues grew into the porous channels of the implant providing vascularization and a secondary method of fixation. The in-grow of vessels into the implant makes it less susceptible to infection and in cases where infection did develop, antibiotics were able to penetrate the implant [Figure 7]. The implants are less prone to capsule formation, and therefore they do not undergo implant shifting due to contracture. Overall, they behave more like bone than any other implant I have employed in my practice. The porous implants were placed following wide dissection, and although this was initially seen as a disadvantage, one must consider this technique as a soft tissue remodeling and reposition. The porous implants are fixed with screws, which do not allow the implant to migrate or move around. I designed implants for each of the different areas of the face [Figure 8]. These implants have given me figuratively and literally an extra dimension to my facial rejuvenation practice.

(2) Imbrication techniques. Subperiosteal dissection is also a great method to lift the composite tissues. Applying sutures to the mid or lower boundaries of the dissected areas they were imbricated and suspended to a higher position. The distance of the lower and higher points of imbrication is decreased while the antero-posterior projection is increased. Examples are browpexy, SOOF lift and mentopexy.

(3) Vascularized fat mobilization. Subperiosteal access also allows manipulation of some of the sagging deep scyssarcosis fat for reshaping. The upper eyelid fat pads are placed over the upper orbital rim augmented brow projection. The lower eyelid fat pads are placed over the lower orbital rim to filled in the tear trough region. The herniated Bichat's fat pad is used to create the Ogee line of the midface.

(4) Fat grafting. With subperiosteal endoscopic techniques there is no associated delamination of the anatomical planes, therefore fat can be injected anywhere from dermis to periosteum. Fat is injected with 1cc Luer-Lock syringes attached to the "Ramirez Super-Luer-Lock micro-cannulas" (Tulip Medical, San 


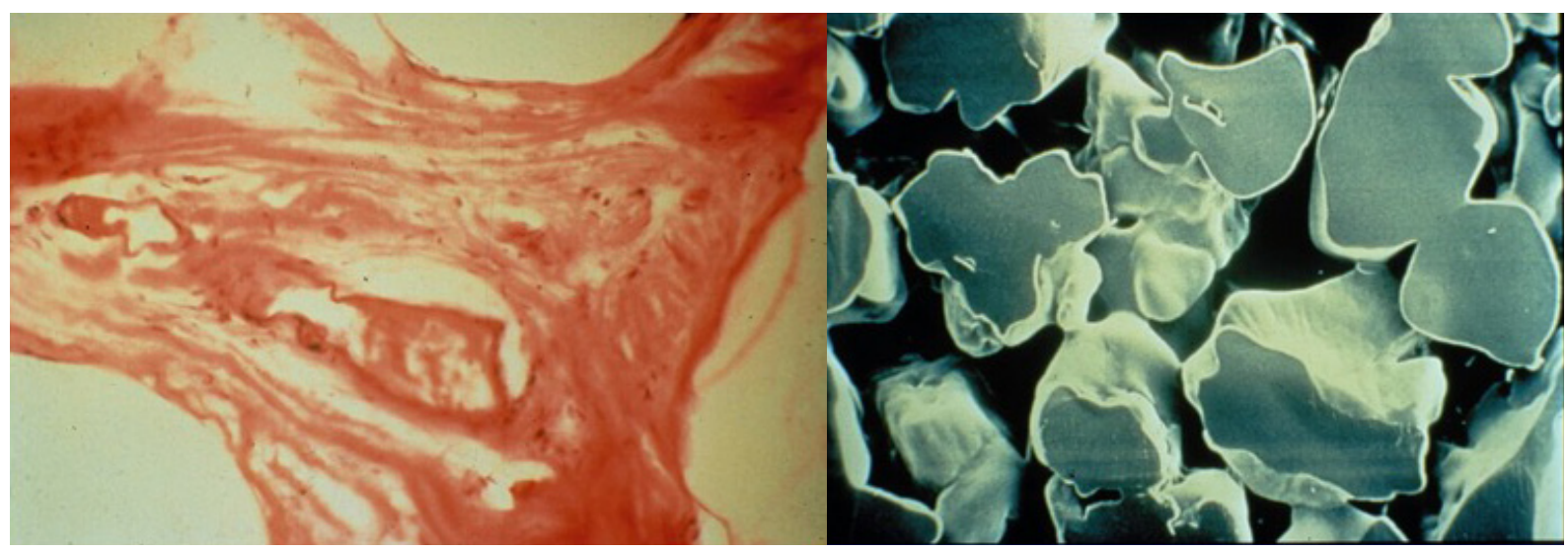

Figure 7. The ingrowth of tissue in the omni-dimensional porous structure of the porouspolypropylene implants

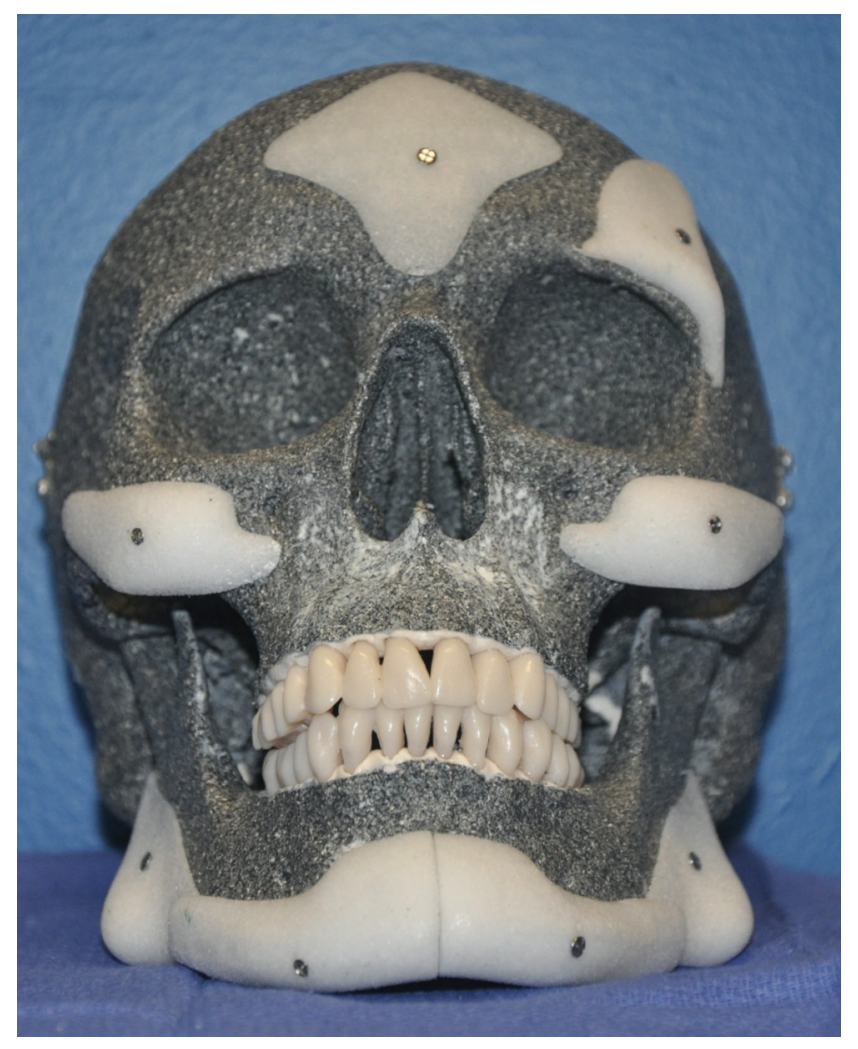

Figure 8. Some of the facial implants designed to provide support and enhance volumein the face

Diego CA). Fat grafting corrected residual asymmetries and erased dermal creases particularly in the nasolabial folds and glabellar lines. An average of $30 \mathrm{cc}$ of fat is sufficient for the entire face, however I use more fat for gaunt faces, or when the imbrication of the Bichat's fat pad elevation did not provide enough volume. Lately I have incorporated stem cell-rich fat grafting obtained with the Diode 1210 laser. This fat is devoid of fibers and can be injected into the dermal/subdermal plane with $1 \mathrm{cc}$ syringes and 23-gauge needles without the need for centrifugation or filtration. We call it Picograft ${ }^{\mathrm{TM}}$ or Picofat $^{\mathrm{TM}[37,38]}$. This $^{\mathrm{T}}$ provided an excellent alternative for skin damaged by sun exposure or smoking, improving skin quality on several fronts: pigmentation, elasticity, and fine wrinkles etc. ${ }^{[37,38]}$. 


\section{Beautification}

Rejuvenation is also a beautification procedure. The three-dimensional enhancement brings back the curves and projection of a youthful and beautiful face. This is different to the stretched look of traditional facelifts. The creation of the ogees of the face is a powerful maneuver to obtain simultaneous beautification and rejuvenation. Other attributes of a beautiful face are angularity and facets, provided by facial implants, in addition to replacing the bony support lost during aging.

\section{Rejuvenation of facial expression}

The subperiosteal repositioning of the point of origin of muscles of facial expression in the entire face gives a generalized happy expression in repose and a gentle smile without effort. These changes arose due to the elevation of the modiolus, lifting of the corner of the mouth. The orbicularis oculi muscles are rotated upwards. The dynamics of the perioral muscles changed when mentopexy or chin implants are integrated during surgery. The origin of the lip depressors and of the lip elevator (Mentalis muscle) are detached and advanced upwards. These steps allow the modiolus to be elevated even further and the lower orbicularis oris to be relaxed, diminishing hypertrophy secondary to orbicularis straining. This allows the lower lip to pout easily. The chin dimples secondary to mentalis straining also disappear creating a youthful, happy look. In my view rejuvenation of facial expression is the ultimate paradigm shift in facial rejuvenation ${ }^{[36,39]}$.

\section{Repositioning of sagging tissues}

Although deflation of tissues has been emphasized as the most important component of aging, sagging of facial tissues is just as important as deflation. The Endotemporo-midface, that includes a periorbitoplasty and a Bichat's fat pad repositioning, elevates most of the sagging structures of the central oval of the face. The effectiveness of midface elevation decreases as the distance from cheek to jawline increased. Therefore, correction of jowls requires additional maneuvers. This is particularly relevant for patients over 50 years of age, who require the addition of traditional cervicofacial lift to remove the excess skin of the lower face and jawline.

My cervicofacial lift includes skin undermining of the neck from side to side across the midline. The platysma with or without a digastric corset is advanced towards the midline and the skin in the opposite direction. Treatment of the submental crease and the marionette lines, requires skin separation from the platysma, allowing unrestricted opposing vectors of pull during repair and closure. I open the deep subplatysmal space in approximately $30 \%$ of my patients. This is done to resect deep fat, treat the enlarged digastric muscles and the enlarged salivary glands. Digastric corset, or shaving, is done for thick digastric muscles. Ptotic and or enlarged submaxillary salivary glands are treated with partial resection or suspension $^{[40,41]}$.

Patients with poor chin and/or mandibular support usually age worse than those that have good support. Moreover, aging produces atrophy of the skeletal support. This is addressed with chin and gonial angle implants. Implants make remodeling of the lower face and neck easier and provide superior aesthetic results. Rejuvenation with implants appear to be more durable. Enhancement of the entire mandible is done using specially designed implants that I named the "Mandibular Matrix Implant System" [Figures 9 and 10] $]^{[42]}$.

\section{Rejuvenation of the skin envelope}

A comprehensive approach also requires skin excision. After improving the foundation with volume augmentation, with any or all of the strategies described, skin excision is more a re-draping maneuver followed by a tensionless closure. This avoids tension bands on the face that give a typical windswept look. The dissected tissues are robust, allowing use of laser resurfacing when required. I also use stem cell richfat graft in the intermediate and subdermal plane without fear of vascular compromise of the skin. 


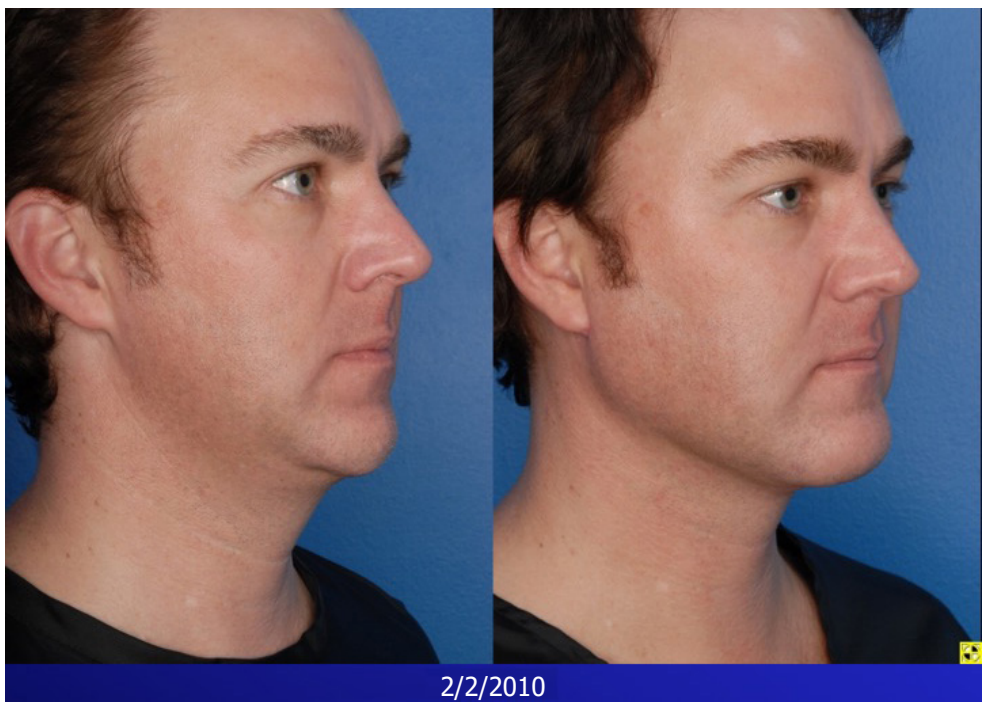

Figure 9. The effect of the Mandibular Matrix System to enhance the lower face, neck and jaw line

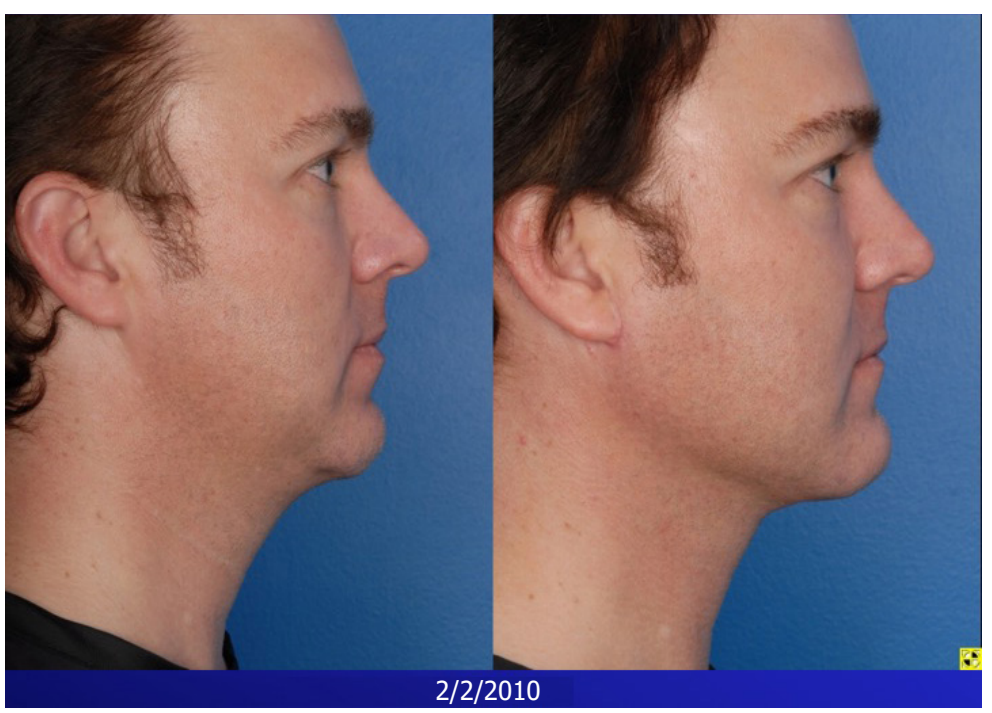

Figure 10. Lateral view of the same patient

\section{Subtractive maneuvers particularly on the neck}

Not everything is augmentation in facial rejuvenation. The jowls and the neck require subtraction. Jowl fat and supra-platysma fat are removed using a small liposuction cannula, preferably under direct visualization. The deep subplatysmal fat is removed only under direct vision. The danger of liposuction in the deep compartment is bleeding, nerve injury or salivary fistula. Its fibrous consistency also makes suction difficult. Fat removal is in a planimetric fashion that includes extension around salivary gland. Isolated fat excision in between the digastric muscles is not advisable as it can lead to cobra neck deformity. The digastric muscles are tangentially shaved or advanced medially to reduce bulk. If salivary glands are found to be enlarged excision can be performed.

The combination of central oval endoscopic with peripheral excisional cervicofacial lift is called BEAM (Biplanar Endoscopic Assisted Mask) facial rejuvenation [Figure 11]. The combination of BEAM facial rejuvenation with Deep Subplatysmal Cervicoplasty is called TEAM (Triplanar Endoscopic Assisted Mask) facial rejuvenation [Figure 12]. 


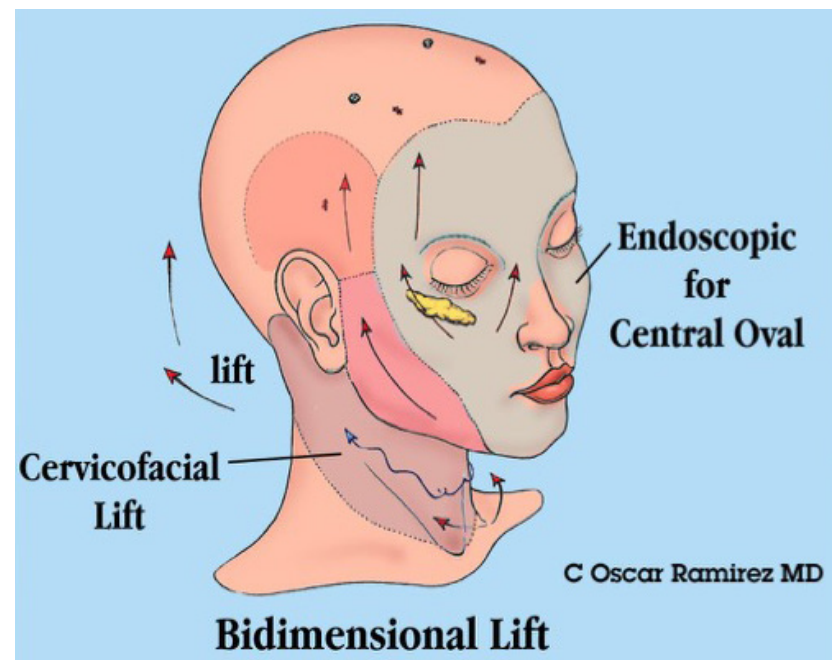

Figure 11. The Biplanar EndoscopicAssisted Mask facial rejuvenation: central oval endoscopic subperiosteal and lowerneck and face subcutaneous open dissection

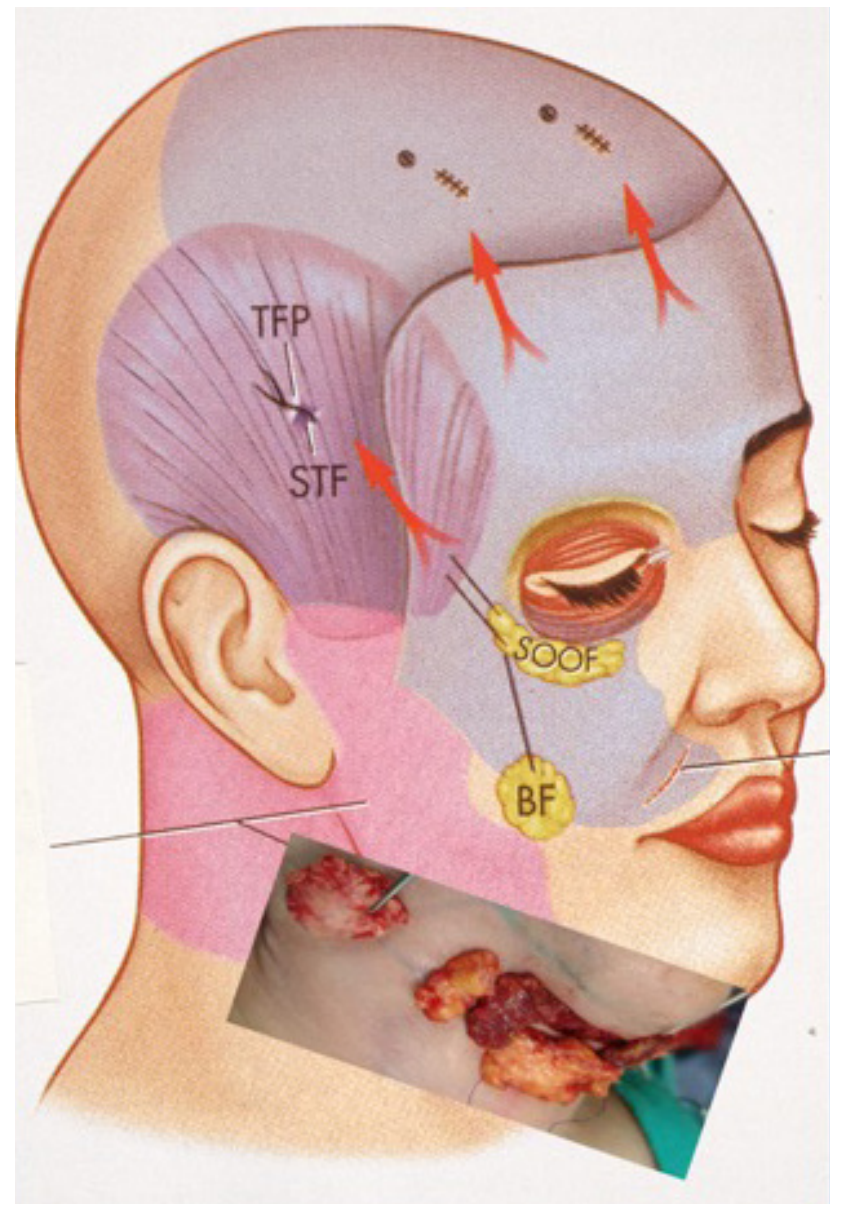

Figure 12. If you add the sub-platysma surgery to the neck, the procedure is called Triplanar Endoscopic Assisted Mask (First published in study ${ }^{[36]}$ ). SOOF: sub-orbicularis oculi fat; BF: Bichat's fat; STF: superficial temporal Fascia; TFP: temporal Fascia Proper 


\section{RESULTS}

I have performed 824 total facial rejuvenation procedures over a 35 -year period. In a random sample of 100 of these cases, independent observers and patient's rated the average number of years of rejuvenation to be 18 (range 11-25 years). This group had a minimum of two years follow-up. Patient satisfaction was excellent in $80 \%$, moderate in $18 \%$ and substandard in $2 \%$.

Refinements in endoscopic techniques over time have resulted in globally low complication rates. Temporary frontal neuropraxia in endoforehead cases was approximately four percent, with function returning in all cases between one and three months. I have had one case of permanent unilateral frontal nerve injury. This was a secondary case after a previous coronal approach. Likewise, neuropraxia of the zygomatic or buccal nerve branches were uncommon, affecting less than two percent of patients. More common were neuropraxia or musculopraxia of isolated muscles of the face, particularly the levator labii superioris (4\%). They were also temporary, recovering by two months on average. Mentopexy, chin and mandibular implants, and deep cervicoplasty all had a combined rate of marginal mandibular neuropraxia of less than three percent. All of these were temporary and likely related to edema or traction. Localized alopecia at the site of scalp access was highly dependent on surgical technique. Silastic port protectors decreased hair follicle damage. Occasionally, patients experienced telogen effluvium, with two cases of near total scalp effluvium that completely resolved after several months. They were related to systemic and localized stresses. Infection was also rare and occurred in less than one percent of cases.

To prevent infection due to bacterial contamination from saliva I use Chlorhexidine gluconate $0.12 \%$ oral rinse twice a day pre-operatively. Intra-operatively I clean the intraoral mucosa with Betadine solution and a diluted solution of Betadine was used in the dissection cavity, applied in neurosurgical sponge pads. I also leave a $2 \mathrm{~mm}$ drain in the cavity with the drain brought out thru a ministab incision in the temporal scalp. If an abscess occurs post-operatively drainage, irrigation and antibiotics are sufficient to manage this complication. I lost some of the lifting effect following removal of the internal suspension sutures. None required reoperations.

Bleeding complications were rare in this endoscopic cohort. One patient developed a moderate volume post-operative hematoma that required drainage but did not require blood transfusion. A few other cases developed minor localized hematomas that were treated by simple aspiration. The overall hematoma rate is less than $1 \%$.

\section{DISCUSSION}

In the last 30 years many advances have been made in the treatment of the aging face. Previously the central oval of the face has been more elusive. The subperiosteal endoscopic approach works beautifully for forehead and midface. The trans-blepharoplasty approach is associated with a high rate of eyelid malposition, but using the endoscopic technique, avoiding eyelid incisions, is almost devoid of this complication $^{[23]}$. Additionally, rates of neuropraxia are less common than those reported in the intermediate layer techniques. The plane of work in sub-SMAS techniques is where the mimetic muscles and nerves are located. Therefore, neuropraxia is common to all sub-SMAS techniques. The subperiosteal plane is deep to these structures. Nevertheless, there are two areas that are still at particular risk: the frontal nerve as it crosses the zygomatic arch and the zygomatic and buccal nerves as they cross over the masseter tendon. The infraorbital nerves can also be injured by blind dissection or excessive traction. Proper technique can significantly reduce these complications. My personal rate of nerve injury on the midface, forehead and mandible is around $2 \%$, highlighting that this procedure can be performed safely and consistently over time. 


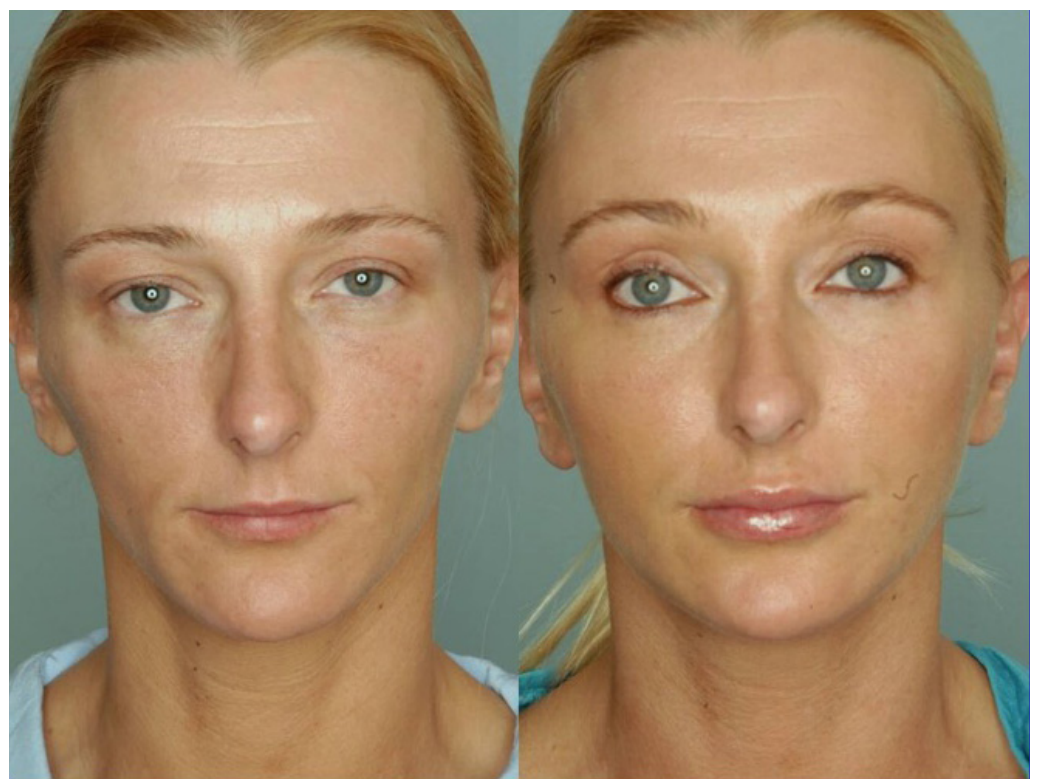

Figure 13. The endoscopic approach to the central oval in younger patients is calledFacial Beautification. Frontal view of a 36 years old female patient

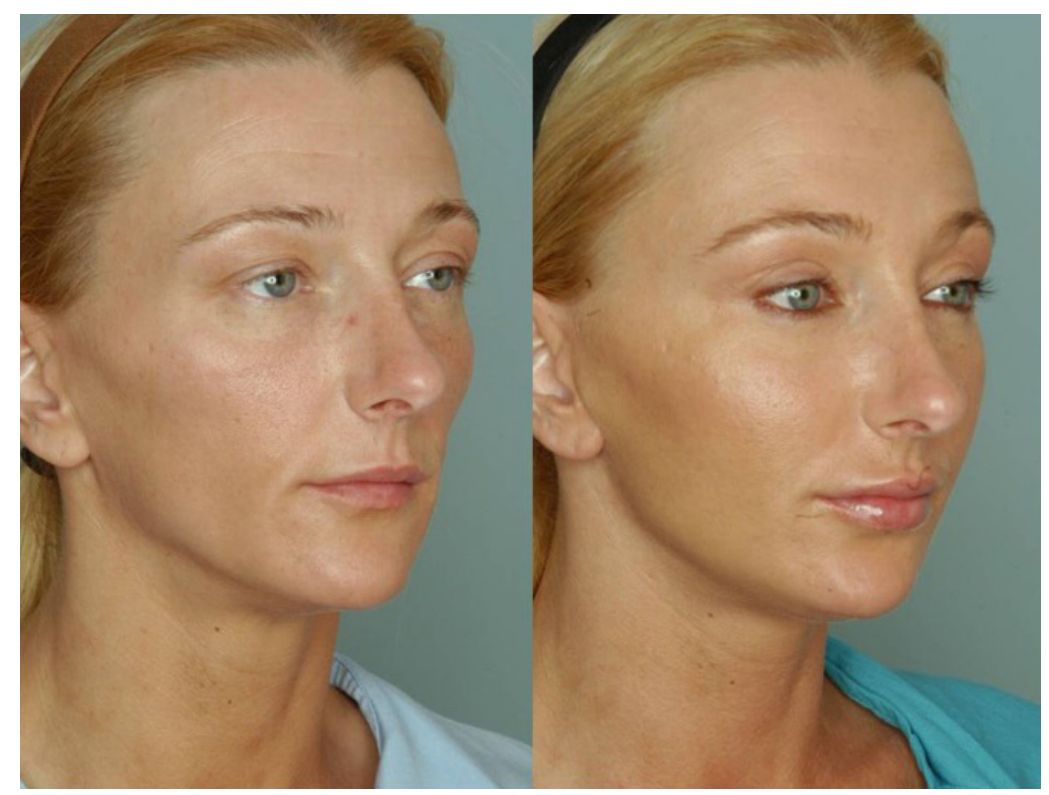

Figure 14. Three quarter view of the same patient. She had endoforehead, endomidface, eyelid ptosis repair and fat grafting to several areas of the face

Endoscopic rejuvenation of the central oval of the face is the cornerstone of facial rejuvenation at any age (young, old, older). These techniques in isolation can provide the objectives of modern facial rejuvenation previously outlined. The central face approach alone is done in patients between early 20's to late 40's. In the very young group we use the same lifting, imbricating and volumetric approach used in older patients. This is done to correct the congenitally prone sagging of the central oval soft tissues. Because lifting or rejuvenation may have negative connotations in this cohort of patients, we call it "facial beautification", because in principle that is what is accomplished [Figures 13 and 14]. One of the advantages of the deeper approach is that you can manipulate the tissues to obtain volume. The brow lift is a remodeling procedure 


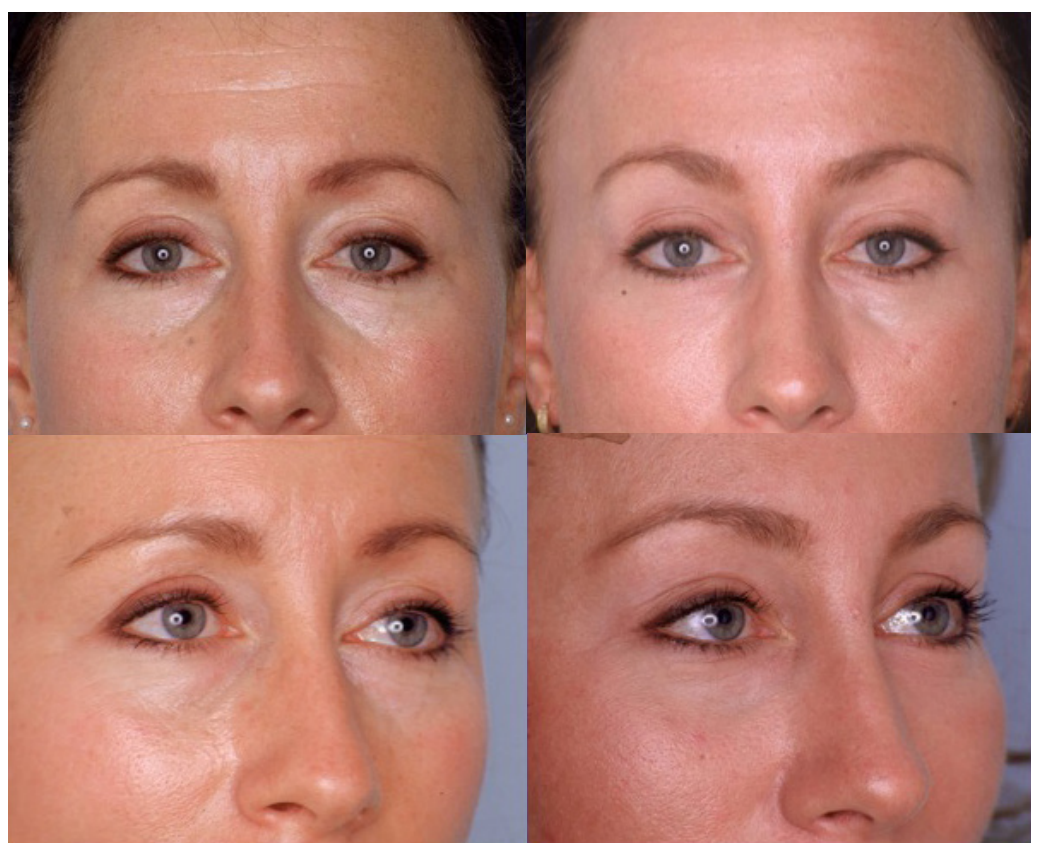

Figure 15. Observe the beautification of the periorbital area. Patient had endoforehead, endomidface and concomitant laser resurfacing of the face. No upper or lowerblepharoplasties were required

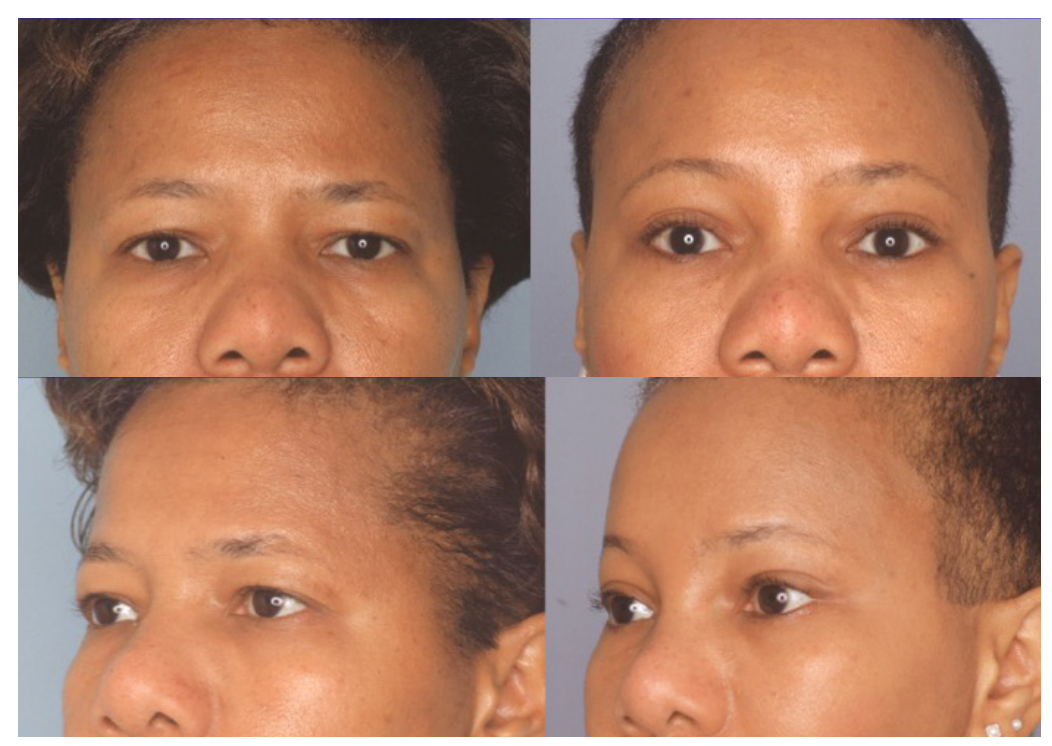

Figure 16. Another patient with endoforehead, endomidface. No upper blepharoplastywas done. Lower blepharoplasty required skin only excision

more than lift. Volume augmentation takes up the anterior-posterior dimension more than the vertical dimension. The forehead lift also relaxes the frontal muscle. Because of the vertical elevation of soft tissues in the midface, it effaces the tear trough deformity. In cases that you need more building material the composite tissues due to the deep dissection allows you inject fat in the intermediate and or superficial planes, Bichat's fat pad can be mobilized over the lower malar area or implants can be introduced to correct different areas (malar, para-nasal, orbital rim). Perhaps these are the most significant differences to other techniques described. In this technique the lower eyelid and midface are treated as one aesthetic unit. It simplifies lower blepharoplasty because you provide support from below and the central SOOF fills-in the tear- 


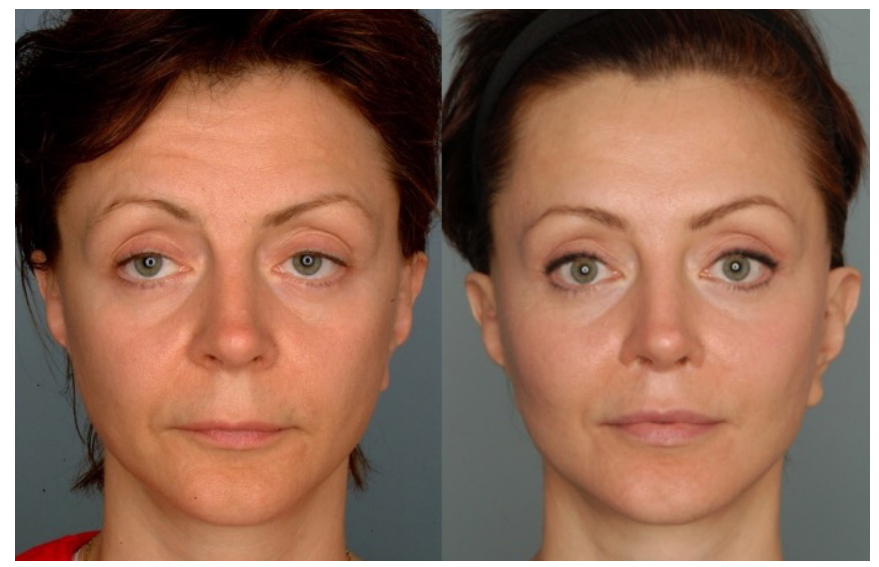

Figure 17. Frontal view of a 48-year-old patient with prior standard facelift three years earlier. Still looks sad, the cheeks are sagging, there is hyperactivity of the forehead, and eyelidptosis (left picture). The post-operative view on the right are two years later observe the rejuvenation of "facial expression"

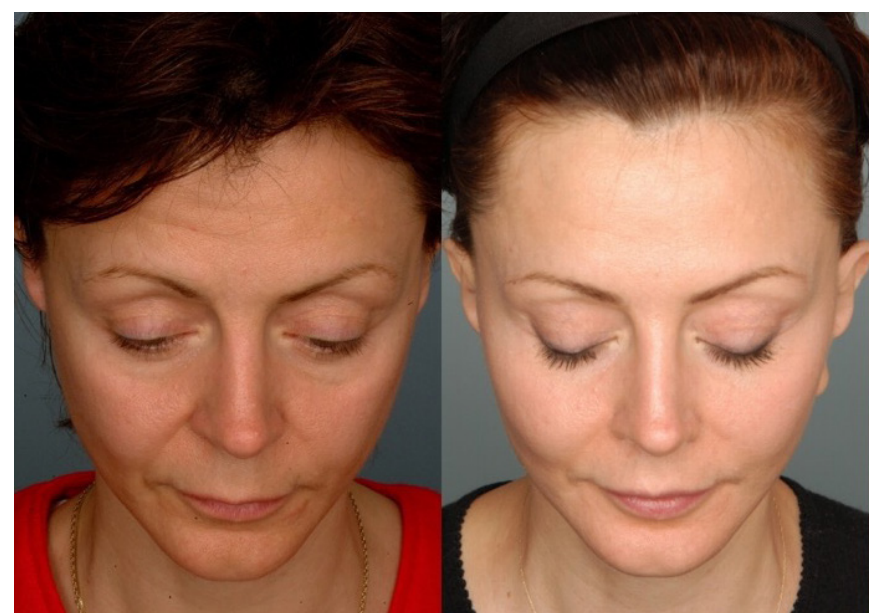

Figure 18. Tilted-down view of the same patient. Before and after views

trough. In that scenario lower eyelid surgery becomes a skin-only operation. Likewise, endoforehead makes upper blepharoplasty unnecessary, or minimizes the amount of skin excision required [Figures 15 and 16]. The case examples [Figures 17-19] demonstrate the exquisite results that can be obtained. Creation of the ogee, blending of lower eyelid-midface interface, natural contour and fullness of the lower eyelids and rejuvenation of the facial expression are features that you do not see consistently with other techniques. The reposition of the facial muscle mask explains changes in facial countenance [Figures 20-22]. Treatment of the lower face and neck can be easily incorporated into the surgical plan. They can be done simultaneously, or if time constraints exist a month later.

After pure endoscopic procedures patients can resume work after about 2-3 weeks. The addition of standard facelift or deep subplatysmal cervicoplasty will increase the amount of swelling and extend the recovery period to about 4-6 weeks. Subtle, subclinical swelling can take up to 6 months to subside. Despite this, the degree of rejuvenation that can be obtained (many times as much as 25 years difference) makes the procedure appealing to those patients that are willing to spend the time and resources for long lasting results and paradoxical "very natural results" [Figures 23-29].

In conclusion, endoscopic techniques of the central oval of the face are the cornerstone of rejuvenation for patients of any age. In my view, addressing the central oval of the face is what makes the major difference. 


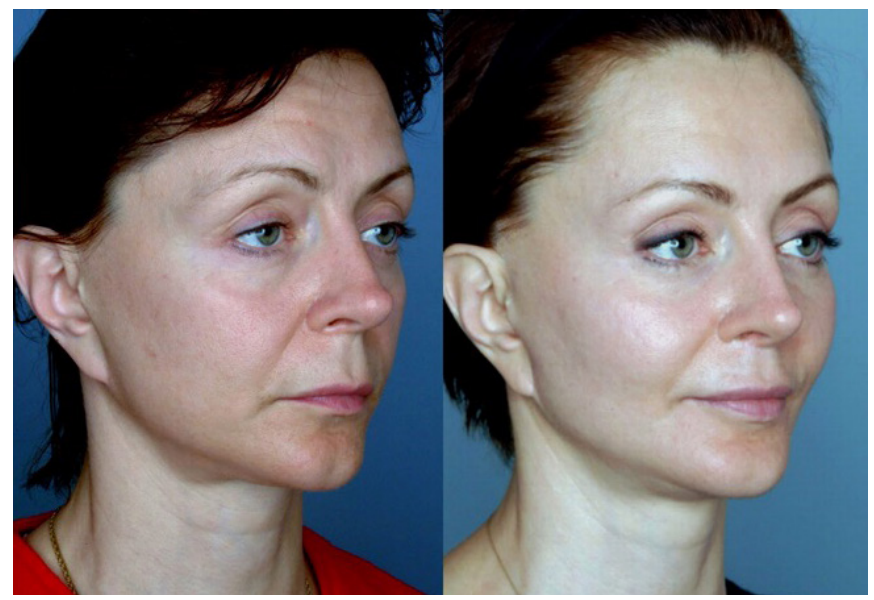

Figure 19. Same patient in three quarter view. Before and after. She underwent endo-forehead, endomidface, eyelid and ptosis repair, lip lift, skin only lowerblepharoplasty and revision of facelift scars

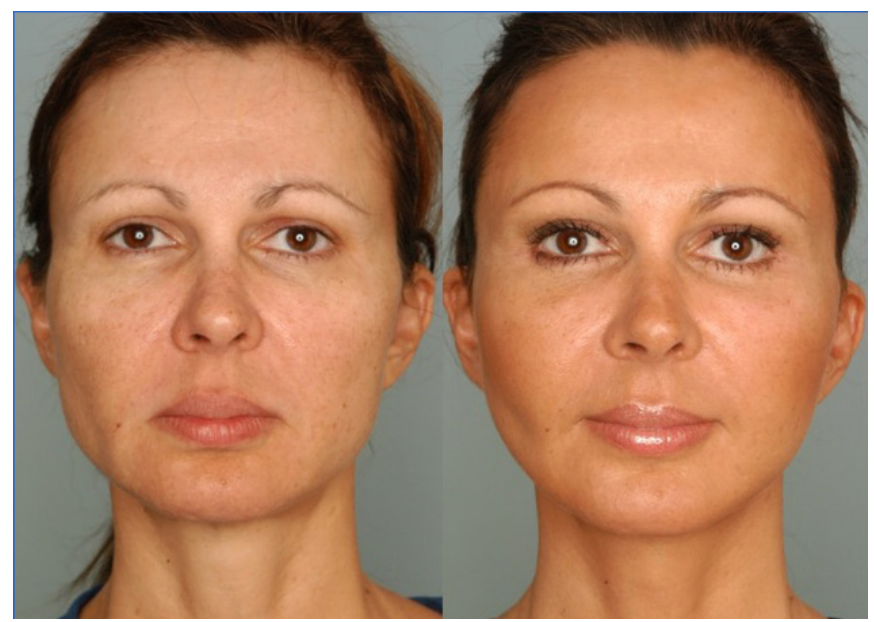

Figure 20. Front vies of a 50-year-old patient, before and after. Patient with history of three prior facial procedures. One standard facelift, one endoscopic midface lift and one redo of midface lift and one fat grafting session to several areas of the face. Patient underwent Biplanar Endoscopic Assisted Mask Facial Rejuvenation. It is not only volumetric restoration or lifting, it is the highest level of rejuvenation: rejuvenation of the facial expression

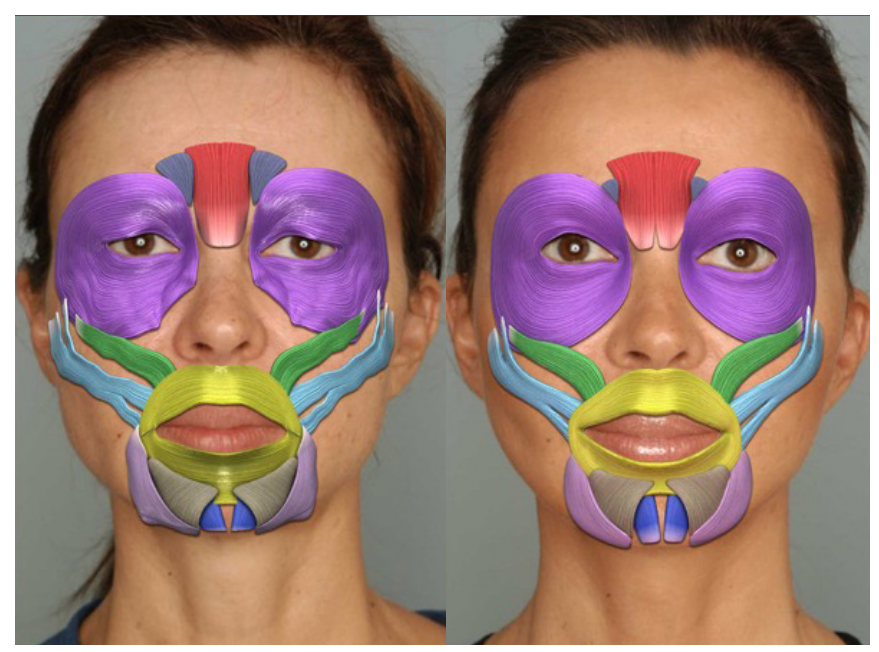

Figure 21. The overlay drawings show the artistic conception of the changes on the muscles of facial expression 


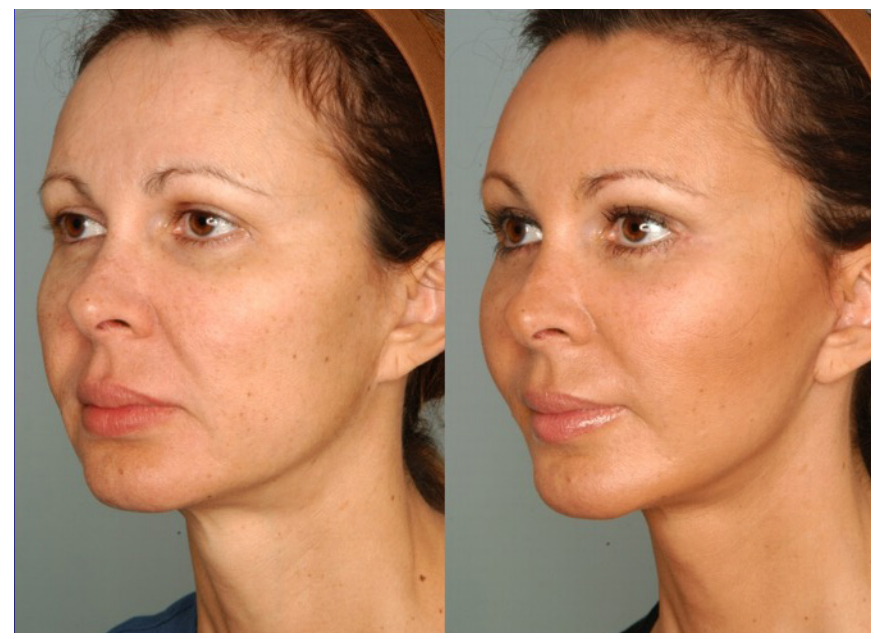

Figure 22. The three-quarter view illustrates these changes better

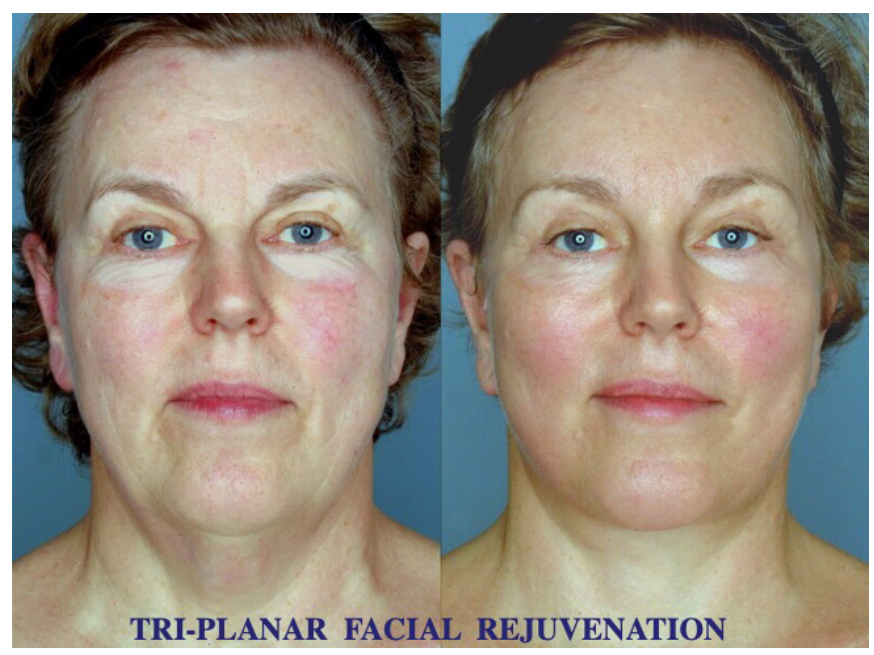

Figure 23. Before and after of a 52-year-old patient. Frontal view. Patient had endoforehead, endomidface, cervicofaciallift and deep subplatysmal cervicoplasty (Triplanar Endoscopic Assisted Mask facial rejuvenation)

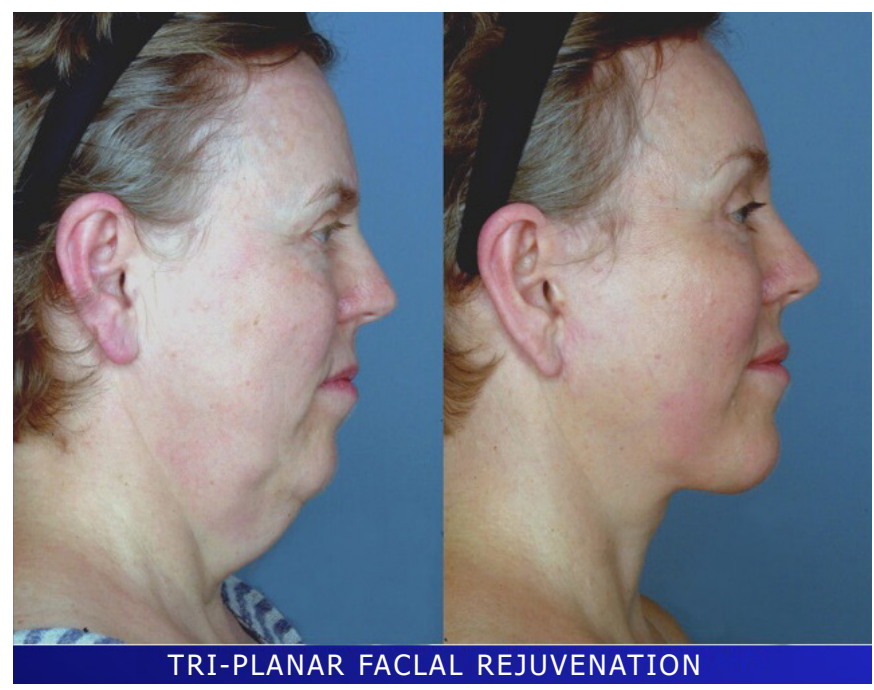

Figure 24. Lateral views of the same patient. Before and after. The neck was addressed by removing deep fat, digastric muscle tangential shaving, and superficial salivary gland excision 


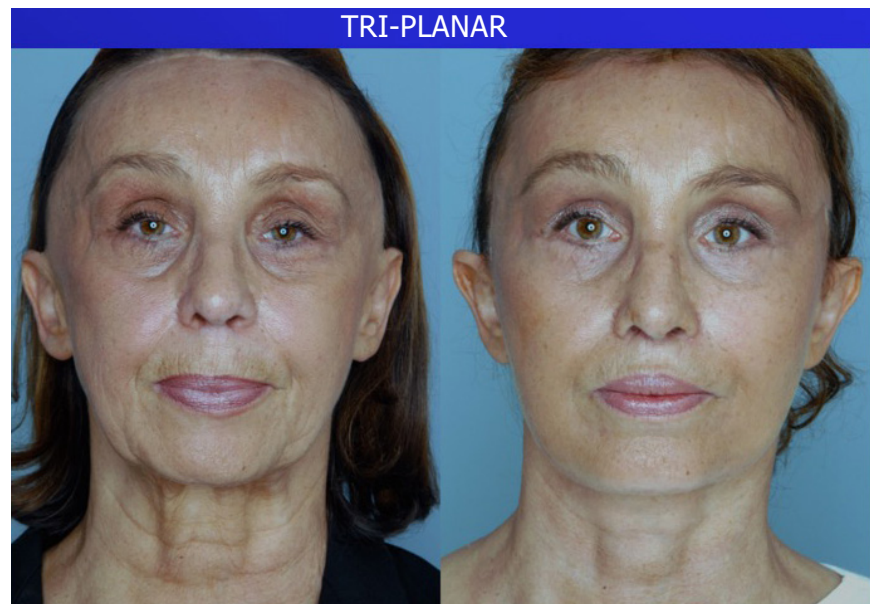

Figure 25. Frontal views, before and after of a 56-year-old edentulous patient with two previous standard face lifts and an anterior hairline brow lift

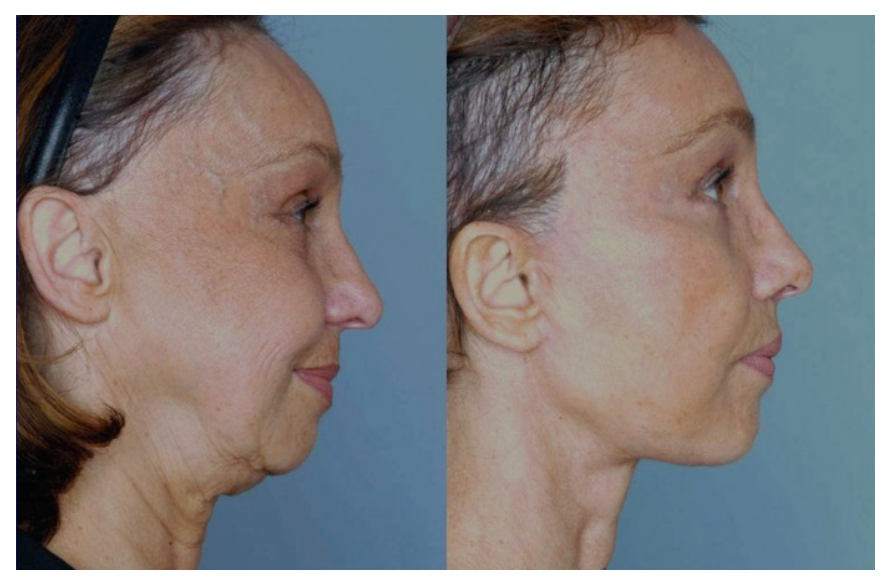

Figure 26. Lateral view of the same patient. Before and after. Observe that she lost the sideburns. The lack of mandibular support is evident. Patient had shortening of the forehead, endomidface, and cervico-facial lift, deep subplatysmal cervicoplasty with fat removal, digastric shaving and partial salivary gland excision. A mandibular matrix implant system was also used. The side burn was recreated with a scalp flap. A lip lift was performed. Eyelid ptosis repair done. Skin only lower lid blephoroplasties were also done

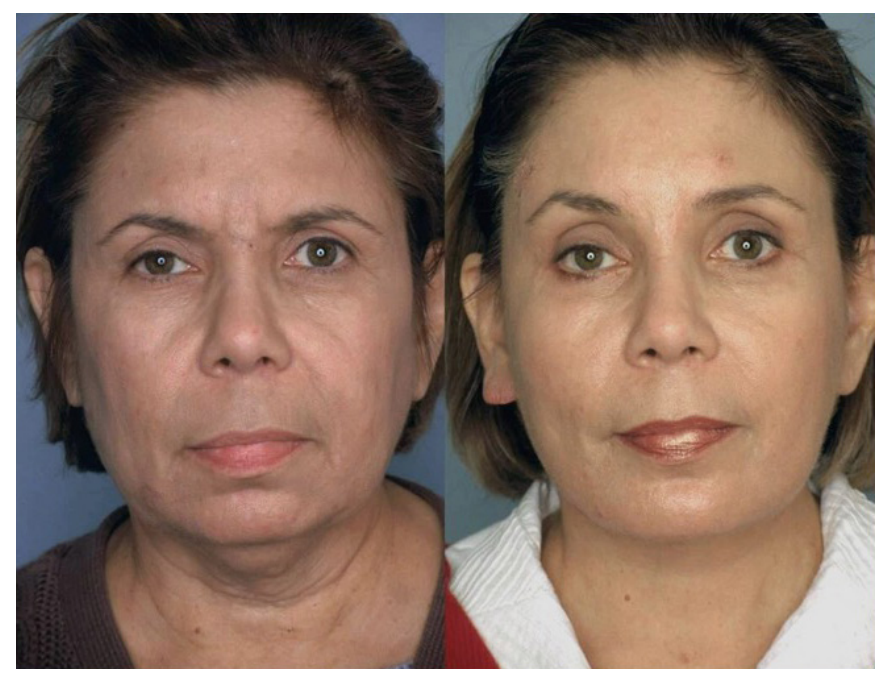

Figure 27. Frontal views of a 54-year-old patient with most of the changes of aging. The comparative before and after photographs demonstrates the significant improvement that can be obtained with a comprehensive facial rejuvenation done using correct planes, vectors of pull, volumetric changes and other ancillary procedures 


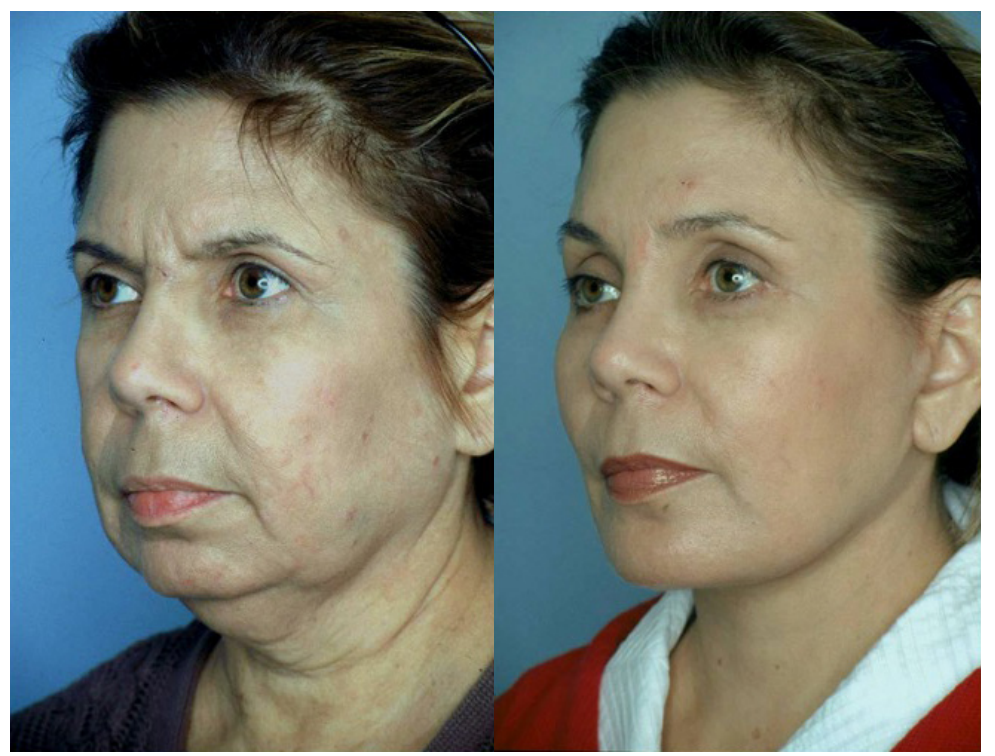

Figure 28. Three quarter view of the same patient. She underwent Triplanar Endoscopic Assisted Mask facial rejuvenation: endoforehead, endomidface,cervicofacial lift, deep subplatysmal cervicoplasty (deep fat removal, digastricshaving and partial salivary gland excision). She also had geniomandibularporous polypropylene implant. No upper blepharoplasty was done. Lower -skin onlyblepharoplasty was performed (First published in study ${ }^{[22]}$ )

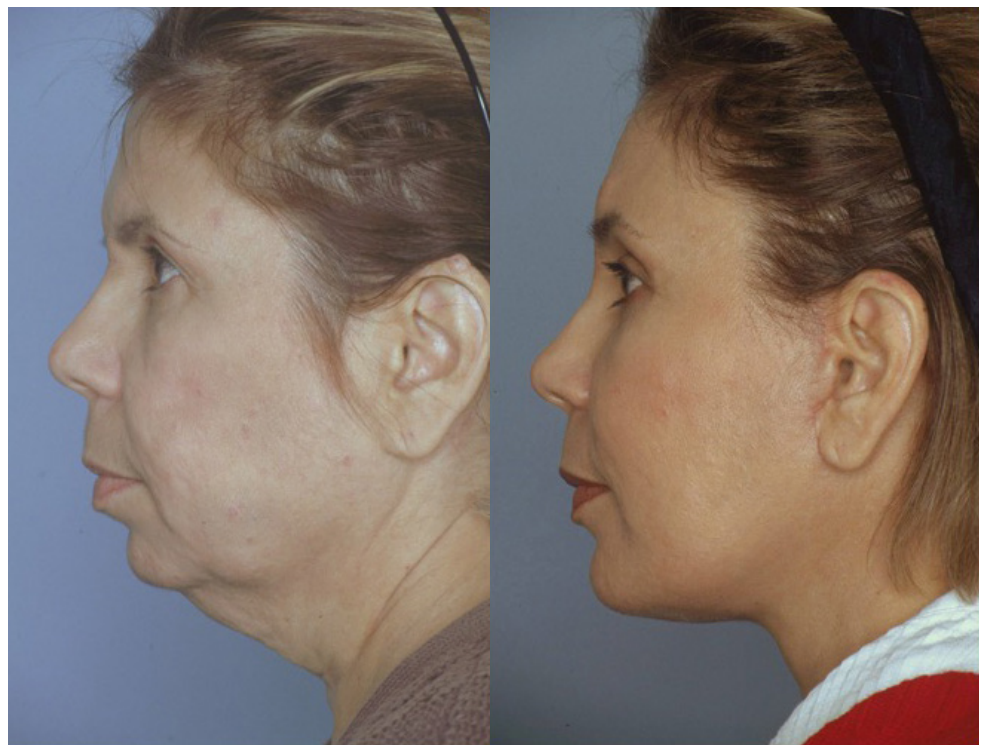

Figure 29. Lateral view of the same patient. Before and after

Patients up to 49 years of age will require only endoscopic techniques. Older patients will require biplanar (BEAM) or Triplanar (TEAM) techniques. Peripheral to the central oval the sagging jowls and excess skin of lower face and neck is approached with a thick-skin rhytidectomy. Problems of the deep neck are approached using a submental incision ${ }^{[40,41]}$. Methods of three-dimensional enhancement can be incorporated easily into any area of the face with any combination of the techniques described above. Damaged skin can be treated with lasers or stem cell-rich fat grafting ${ }^{[18,20,37,38]}$. Despite the comprehensive and seemingly aggressive approach the results show few telltale signs of an operated look and has longterm, durable results. 


\section{DECLARATIONS}

\section{Authors' contributions}

The author contributed solely to the article.

\section{Availability of data and materials}

Not applicable.

\section{Financial support and sponsorship}

None.

\section{Conflicts of interest}

Consultant for Marina Medical. Davie, Florida.

Consultant for "Villani Spongilla Matrix". Newport Beach, California.

Consultant for Poriferous (Facial Implants). Newnan, Georgia.

Speaker Bureau \& Technical Support DMC.

Founder \& Co-owner of "Laser Stem Cell Technologies LLC".

\section{Ethical approval and consent to participate}

Not applicable.

\section{Consent for publication}

A written informed consent for publication has been obtained from patients.

\section{Copyright}

(C) The Author(s) 2020.

\section{REFERENCES}

1. Skoog T. Useful Techniques in Face-lifting. Presented at the meeting of the American Association of Plastic Surgeons; San Francisco, Calif. April 1969.

2. Lemmon, Mark L. (Mark Leonard). Color atlas of SMAS rhytidectomy. Thieme Medical, G. Thieme Verlag, 1993.

3. Mitz V, Peyronie M. The superficial Musculo-Aponeurotic System (SMAS) in the parotid and cheek area. Plast Reconstr Surg 1976;58:80-8.

4. Hamra ST. The deep-plane rhytidectomy. Plast Reconstr Surg 1990;86:53-61; discussion 62-3.

5. Hamra ST. Composite rhytidectomy. Plast Reconstr Surg 1992;90:1-13.

6. Baker DC. Deep dissection rhytidectomy: a plea for caution. Plast Reconstr Surg 1994;93:1498-9.

7. Tessier P. Le lifting facial sous-perioste. Ann Chir Plast Esthet 1989;34:193-7. (in French)

8. Psillakis JM, Rumley TO, Camargos A. Subperiosteal approach as an improved concept for correction of the aging face. Plast Reconstr Surg 1988;82:383-94.

9. Ramirez OM, Maillard GF, Musolas A. The extended subperiosteal face lift: a definitive soft-tissue remodeling for facial rejuvenation. Plast Reconstr Surg 1991;88:227-36; discussion 237-8.

10. Ramirez OM. The subperiosteal rhytidectomy: the third-generation face-lift. Ann Plast Surg 1992;28:218-32; discussion 233-4.

11. Krastinova D. Lifting facial sous-perioste. Ann Chir Plast Esthet 1989;34:199-211.

12. Santana PSM. Metodologia craneomaxilofacial en Ritidoplastias. Cirugia Plastica Ibero-Latino Americana 1984;10:321.

13. Ramirez OM. Extended Subperiosteal Facelift. Presented at the Xth Biannual Congress of the International Society of Aesthetic Plastic Surgery. Zurich, Switzerland. September 1989.

14. Vasconez LO, Core GB, Gamboa-Bobadilla M, Guzman G, Askren C, et al. Endoscopic techniques in coronal brow lifting. Plast Reconstr Surg 1994;94:788-93.

15. Ramirez OM. Anchor subperiosteal forehead lift: from open to endoscopic. Plast Reconstr Surg 2001;107:868-71.

16. Ramirez OM. Endoscopic techniques in facial rejuvenation. An overview: Part I. Aesthetic Plast Surg 1994;18:141-7.

17. Ramirez OM. Endoscopic full facelift. Aesthetic Plast Surg 1994;18:363-71.

18. Ramirez OM, Pozner JN. Subperiosteal minimally invasive laser endoscopic rhytidectomy: the SMILE facelift. Aesthetic Plast Surg 1996;20:463-70.

19. Ramirez OM, Pozner JN. Subperiosteal endoscopic techniques in secondary rhytidectomy. Aesthet Surg J 1997;17:22-6. 
20. Ramirez OM, Pozner JN. Laser resurfacing as an adjunct to endo-forehead lift and biplanar facelift. Ann Plast Surg 1997;38:315-22.

21. Ramirez OM, Pozner JN. High-tech facelift. Aesthetic Plast Surg 1998;22:318-28.

22. Ramirez OM. Full face rejuvenation in three dimensions: a "face-lifting" for the new millennium. Aesthetic Plast Surg 2001;25:152-64.

23. Ramirez OM. Three-dimensional endoscopic midface enhancement: a personal quest for the ideal cheek rejuvenation. Plast Reconstr Surg 2002;109:329-40.

24. Ramirez OM. The central oval of the face: tridimensional endoscopic rejuvenation. Facial Plast Surg 2000;16:283-98.

25. Aiche AE, Ramirez OM. The suborbicularis oculi fat (SOOF): an anatomical and clinical study. Plast Reconstr Surg 1995;95:37-42.

26. Ramirez OM, Santamarina R. Spatial orientation of motor innervation to the lower orbicularis oculi muscle. Aesthetic Surg J 2000:10713.

27. Knize DM. An anatomically based study of the mechanism of brow ptosis. Plast Reconstr Surg 1996;97:1321-33.

28. Ramirez OM. Fourth generation subperiosteal approach to the midface: the tridimensional functional cheek lift. Aesthetic Surg J $1998 ; 8: 133-5$.

29. Ramirez OM. Buccal fat pad pedicle flap for midface augmentation. Ann Plast Surg 1999;43:109-18.

30. Carruthers A, Carruthers J. Aesthetic indications for botulinum toxin injections. Plast Reconstr Surg 1995;95:427-8.

31. Narins RS, Brandt F, Leyden J, Lorenc ZP, Rubin M, et al. A randomized, double-blind, multicenter comparison of the efficacy and tolerability of Restylane versus Zyplast for the correction of nasolabial folds. Dermatol Surg 2003;29:588-95.

32. Ramirez OM. What is wrong with aesthetic approach to facial volumization: a judgement to the hollywood legacy. Presented at the 54th Brazilian Congress of Plastic Surgery. Florianopolis, SC Brazil. November 15-18, 2017.

33. Ramirez OM, Volpe CR. Double ogee facial rejuvenation. In: Panfilov DE, editor. Aesthetic surgery of the facial mosaic. Berlin: SpringerVerlag; 2007. pp. 288-99.

34. Hurwitz DJ, Raskin EM. Reducing eyelid retraction following subperiosteal face-lift. Aesthet Surg J 1997;17:149-56.

35. Ramirez OM. Tezel E, Ersoy B. The Peruvian fisherman's knot: a new, simple, and versatile self-locking sliding knot. Ann Plast Surg 2009;62:114-7.

36. Ramirez OM. Treating the aging face: "high definition-high tech" comprehensive facial rejuvenation. MKG-Chirug 2019;12:68-77.

37. Ramirez OM, Centurion P. Super rich stem cell-fat grafting procured by a novel laser technology: a paradigm shift in aesthetic surgery and regenerative medicine. Presented at the 2018 Bi-Annual ISAPS Congress. November, 2018, Miami, Florida.

38. Ramirez OM, Centurion P. Super Rich Stem Cell-Fat Grafting Procured by a Novel Laser Technology: A Paradigm Shift in Aesthetic Surgery and Regenerative Medicine. Abstract at the Annual Meeting of the American Society for Aesthetic Plastic Surgery. New Orleans, LA. May, 2019.

39. Ramirez OM. Rejuvenation of the Facial Expression: The Ultimate Paradigm Shift in Facial Surgery. Presented at the International Symposium, "All About Face 2019”, Curitiba, Brazil, August 2019.

40. Ramirez OM. Advanced considerations determining procedure selection in cervicoplasty. Part two: surgery. Clin Plast Surg 2008;35:691-709.

41. Ramirez OM. Multidimensional evaluation and surgical approaches to neck rejuvenation. Clin Plast Surg 2014;41:97-105.

42. Ramirez OM. Mandibular matrix implant system: a method to restore skeletal support to the lower face. Plast Reconstr Surg 2000;106:176-89. 